\title{
The Effect of Unit-of-Translation on Iranian Upper-Intermediate EFL Learners' Achievement in Bizarre News Translation
}

\section{Ehsan Eshtiyaghi ${ }^{1} \&$ Abbas Pourhosein Gilakjani²*}

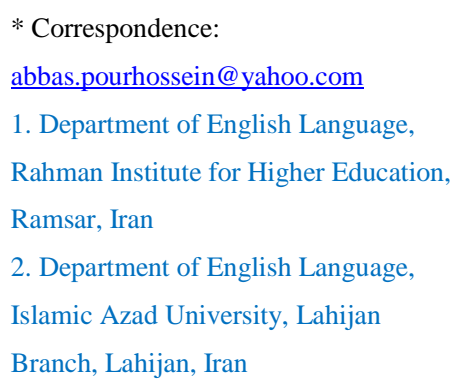

Received: 16 December 2020

Revision: 12 February 2021

Accepted: 2 March 2021

Published online: 20 March 2021

\begin{abstract}
The current study was an attempt to investigate whether the Unit-ofTranslation has any effect on Iranian upper-intermediate EFL learners' achievement in Bizarre News translation. In addition, it investigated whether there was any difference across gender regarding the effect of Unit-ofTranslation on Iranian upper-intermediate EFL learners' achievement in Bizarre News translation. To this end, 45 out of 88 EFL learners from three upper-intermediate language learners at two Language Institutes in Boumehen, Iran were selected based on Oxford Placement Test. Then, they were divided randomly into three groups; one control group $(\mathrm{N}=15)$ and two experimental groups $(\mathrm{N}=30)$. The first experimental group was male. The second experimental was female, and the third group was administered as the control group. The experimental groups received the instruction for unit of translation. The instruction was given in five sequential sessions about 50 minutes. In contrast, the control group received no special instruction. At the end of the course, a post-test was administered. To analyze the data, oneway ANOVA and independent samples t-test were run. The findings revealed that the Unit-of-Translation had a positively significant effect on Iranian upper-intermediate EFL learners' achievement in Bizarre News translation. The results also indicated that concerning the effect of Unit-ofTranslation on Iranian male upper-intermediate EFL learners had a better achievement in Bizarre News translation compared to their counterparts in the female group.
\end{abstract}

Keywords: Unit-of-Translation; Bizarre news translation; EFL learners 


\section{Introduction}

When a text is being translated it is usually segmented into smaller parts which are easy and convenient to translate. Such segments of a text are known as units of translation. Though the unit of translation is one of the basic notions of translation which is widely used in books on translation, there is no universally accepted definition of it even today. One of the foreign pioneers of the theory of translation (Catford, 1965) introduced the term 'rank of translation' in his book "A Linguistic Theory of Translation" which was used in a similar meaning. Still debatable today is the problem of terminology to be used in regard to this notion which is shown in many studies. Some scholars, for example, contrast the terms transleme, which is established in a Source Language (SL) text, and unit of translation which is found in a Target Language (TL) text. According to Tyulenev (2007), the unit of translation should be termed translateme and defined as "a combination of a linguistic unit of the source language expressing a certain contextual meaning and the minimal corresponding linguistic unit of the target language with the same meaning" (p. 333). Some scholars confine the understanding of the unit of translation only to problem units of a text.

The term 'unit of translation' was first used by Doherty (1999) who claimed that its size may be variable as it serves only practical purposes. In this connection, Torop (1995) who investigates translation in close connection with language and culture points out that for a translator/interpreter it is necessary to operationally distinguish elements of culture and language both on the level of a text and the level of language units. A language is integrated in culture in which it functions (Brown, 2000; Karimnia \& Heydari Gheshlagh, 2020; Sikander, 2018), it is necessary to identify cultural and language features separately and later establish correlations between them. In the approach to this central notion of translation theory it is reasonable to keep apart three aspects of the unit of translation that should be discussed separately and not confused as they arouse their own particular problems:

(1) theoretical: its understanding and definition which should take into account the most important features of a unit of translation,

(2) size-of-the-unit: relation of a unit of translation to language levels, and

(3) operational: criteria applicable in the process of their identification in a Source Language Text (SLT), i.e. segmenting a SLT into textual elements that are convenient to translate.

The definition of the unit of translation may be given from three points of view: 1) with reference to a SLT, 2) with reference to a TLT, and 3) with reference to both a SLT and a TLT. Within the above three approaches, scholars may take into account various criteria: (a) content, (b) form, or (c) both content and form. The first aspect of the unit of translation is connected with its definition. The most well-known definition of the unit of translation based on the criterion of content with reference to a SLT was suggested by Vinay and Darbelnet (1965). According to them, a unit of translation is a unit of sense. The criterion of form is very important in form-oriented translation when formal peculiarities serve as an additional channel of conveying some information, e.g. English favors alliteration as a stylistic device which it is possible to render in translation often at the expense of its content. With reference to a TLT, definitions of the unit of translation first appeared in the works of scholars who tackled the problems of machine translation. A unit of translation was understood as a combination of certain lexemes and grammemes which correspond to a certain lexical or grammatical category in TLT. The most wide-spread definition based on these criteria was given by Barkhudarov (1975). It runs as follows: "It is a minimum language unit in a SLT which taken as a whole has a certain correspondence in TLT, but the constituent parts of which taken separately do not have a correspondence with a similar meaning in a TL" (Barkhudarov, 1975, p.175).

Through understanding the category of LTT, it is necessary to stress its main features which are as follows: (a) a unit of translation should always be found in a SL text, not in a TL text, (b) it is established as a special category relevant from a translator's point of view and therefore it has no correlation with the existing language levels, and (c) it is a minimum unit in a sense that it cannot be segmented in translation into smaller parts without detriment to its sense. The second aspect of the unit of translation has to do with its relationship with language levels. At present, there are various approaches to the solution of this problem. Some scholars believe that the unit of translation is always larger than a separate word. It may be a sentence or a clause, a group of sentences, a paragraph or even a whole text. This point of view is supported by Retsker and Komissarov (1989). They claim that a word cannot be chosen as a unit of translation for several reasons: 1) its boundaries are not always clear-cut; 2) words blend together in speech forming various semantic and structural complexes, the elements of which must be viewed together by a translator in order to 
retain in translation the meaning of a whole unit; and 3) the outer (formal) aspect of a speech event to be rendered in translation may be often more important than the semantic one.

Komissarov (1999) points out that a sentence is usually chosen as an operational unit of translation since it provides a micro-context necessary and sufficient to comprehend its meaning properly. He admits the possibility of choosing other units of translation within a sentence which are of a lower rank, and associated with a word-level or a wordgroup level. In other words, the author introduces the idea of hierarchy of units of translation which may be chosen on different levels (higher and lower). Reiss and Vermeer hold that a unit of translation should be chosen on the level of a text as it may help to overcome contextual ambiguity and ambivalence of words and even sentences that arise from differences in languages and cultures; a text realizes the speaker's intention. Thus, in conclusion it must be stressed that the unit of translation should not be tied in with any particular language level since as has been shown above it can be located on various levels on the condition that it satisfies the criteria and requirements stated in the quoted definition. The third important aspect of a unit of translation is connected with criteria on which a translator may rely in order to identify it in the process of segmenting a SL text. The analysis of various approaches testifies to diverging solutions to this problem. Most translatologists contend that such criteria do not include the criterion of the size of a unit of translation as it is variable in various translation acts. Some linguists connect the size of the unit of translation not with a SLT, but with the capacity of the TL to express the same notion that is expressed in the original.

In search of reliable criteria, some linguists associate units of translation with translation problems, hence the only criterion of a unit of translation is claimed to be connected with its being sufficient for making proper translation solutions. In other words, units of translation call for an individual translation solution. Such an approach to the criteria of a unit of translation was elaborated by Breus (2005) who defined units of translation in connection with a text which is viewed as a matrix of translation problems. This matrix covers problem translation areas and problem-free translation areas. In the former case, a translator deals with units of translation which he has to translate creatively and of his own accord, while in the latter case he transcodes a text using regular correspondences according to Retsker's (1989) theory. Thus, apart from the theoretical aspects of understanding and defining a unit of translation, there arise practical difficulties associated with segmenting a SLT into minimal translation units. It is obvious that the knowledge of SL and TL systems alone is not sufficient to cope with this task. In fact, the process of segmenting a SL text into units of translation should be viewed as a multi-stage procedure the success of which depends to a great extent on both linguistic and extra-linguistic factors. As a rule, translatologists establish three stages in this process: 1) considering linguistic units of a certain level (usually words), 2) evaluating their contextual interdependence, and 3) modifying it in various ways (enlarging initially chosen linguistic units to the size of word-combinations, sentences and even entire paragraphs and texts; or diminishing them and choosing on a lower level or combining several into one; or dropping in translational).

It is believed that it is not enough to take into account only linguistic factors (systemic and contextual), but it is also necessary to pay attention to such important aspects of translator's activity as translation norm, situational and broader cultural parameters which determine the sense and implications of a SL text affecting the choice of proper units of translation on a given occasion. Thus, in connection with these factors and parameters of a SLT it is possible to single out the following stages in the text-segmentation procedure: 1) Segmenting a text, depending on our knowledge of the language, into minimal units of sense (in regard to meaningful language units) or minimal units of outer expression (phonemes or graphemes), which cannot be further segmented into smaller parts without detriment to either sense or form, 2) Analyzing all contextual modifications of established semantic and formal features of those units, 3) Considering all situational and background factors which determine particular uses of the established units, 4) Enlarging, diminishing or dropping selected units of translation under the influence of translation norms as a verification of their correct choice in a given context, 5) Applying the principle of interchangeability, and 6) taking into account the addressee.

Thus, it is apparent that segmenting a SLT into units of translation is a complicated procedure of its interpretation which is the decisive factor of adequate rendering in a TL and at various stages the SLT analysis and segmentation into parts depend upon both linguistic and non-linguistic factors. In fact, the discussion of the unit of translation should bring to light its main aspects: theoretical (connected with the understanding and definition of this notion), the sizeof-the-unit aspect (connected with the choice of units of translation on different language levels on the basis of identificatory criteria), and operational aspect (connected with principles of segmenting a SLT into units of translation). Regarding the nature of translation, it seems that most Iranian translators are not aware of the exact unit of translation. Thus, the current study was an attempt to fill such gap in literature, and investigate whether instruction 
based on unit of translation has any significant effect on the quality of translation in general and Bizarre news in particular.

\subsection{Research Questions}

To meet the objectives of this study, the following research questions were posed:

RQ1. Does the Unit-of-Translation have any significant effect on Iranian upper-intermediate EFL learners' achievement in Bizarre News translation?

RQ2. Is there any significance difference across gender regarding the effect of Unit-of-Translation on Iranian upperintermediate EFL learners' achievement in Bizarre News translation?

\subsection{Null Hypotheses}

To fulfill the aim of the study practically through the above-mentioned research questions, the following null hypotheses were considered.

HO1. The Unit-of-Translation has no significant effect on Iranian upper-intermediate EFL learners' achievement in Bizarre News translation.

HO2. There is no significance difference across gender regarding the effect of Unit-of-Translation on Iranian upperintermediate EFL learners' achievement in Bizarre News translation.

\section{Review of the Literature}

The earliest study to define unit of Translation was by Vinay and Darbelnet (1995). They define a translation unit as 'the smallest segment of the utterance whose signs are linked in such a way that they should not be translated individually' (1995, p. 21). Similarly, Barkhudarov defines it as the 'minimal' (1993); Newmark as the 'smallest' (1988b); and Toury as the 'manageable' (1986). This is actually an alternative way to distinguish the lexical sense of translation unit from the cognitive one. The former is smaller than the latter; therefore, by defining translation unit as 'smallest', linguists manage to cut off the cognitive sense of translation unit and therefore imply that a translation unit is a lexical unit.

According to Shuttleworth and Cowie (1997), a translation unit is the linguistic level at which ST is recodified in TL. Since the term 'smallest' is not very well defined, it is preferable to define the translation unit as a 'lexical' unit. The third point is whether the translation unit is a syntactic and semantic unit, or either of them. Barkhudarov (1993) raises the issue of whether translation units are 'elements of linguistic form (structure) or content.' He does not clearly state his answer and defines a translation unit as the 'language' unit, which is rather ambiguous. On the other hand, Vinay and Darbelnet clearly maintain that translation units are both syntactic and semantic units; 'lexicological units within lexical elements are grouped together to form a single element of thought' (1995, p. 21).

Teubert (2001) also agrees with this view that content cannot be separated from form. The fourth point is how to call the corresponding segment of a translation unit in the translated text. The majority of theorists use the term 'equivalent': 'TL equivalent' (Newmark, 1988b, p. 65), 'equivalent' (Barkhudarov, 1993, p. 40), and 'translation equivalent' (Teubert, 2004, p. 185). On the other hand, some theorists use other terms such as 'TL segment' (Toury, 1986, p. 83), 'corresponding segment' (Toury, 1986, p. 88), and 'TL unit' (Shuttleworth \& Cowie, 1997; Vinay \& Darbelnet, 1995). Taken into account that equivalence is found in translated texts, the term 'translation equivalent' is more accurate; this helps distinguish it from the other types of equivalents (Altenberg \& Granger, 2002).

The UT has been a subject of debate since it was raised and defined by Vinay and Darbelnet in 1958. According to them $(1958$, p. 22), the UT is "the smallest segment of the utterance whose signs are linked in such a way that they should not be translated individually." Hatim and Munday simply call it "normally the linguistic unit which the translator uses when translating" (2004, p. 25). Snell-Hornby (1995, p. 16) calls the UT "a cohesive segment lying between the level of the word and the sentence." UTs claimed by scholars range from the culture of the language to the whole text to the morpheme, with Newmark alleging that "all lengths of language can be used as units of translation but "operatively, most translation is done at the level of the smaller units (word and clause)" (1988, pp. 66-67).

Huang claims that in Chinese-English translation "the best UT is the paragraph" (2002, p.544). Developing translation theory, especially translation quality assessment (TQA) models without knowing the UT is no different from studying medicine without knowledge of the human cell. Success is possible but may be accidental. Identifying the UT is an 
attainable task, though not by repeating old definitions and citing confusing opinions. Two favorable conditions have long existed, which are the abundance of translations available in public libraries and bookstores, and the large number of professional translators throughout the world.

Matthiessen assumes that "the clause (complex) [sentence as called in traditional grammar] is a likely candidate as the "unit of translation" (2001, p.116). He further defined UT as a TT segment instead of the commonly accepted ST segment, as follows: (1) the UT creates an interval in the translating process, (2) it is into which the translator renders from the ST, (3) it has distinct and consistent grammar features, and (4) it possesses presence of meaning which is identifiable, and accuracy which is measurable through standardized assessment. In summary, the UT bears universal features, plays a consistent role in the construction of translation, and has measurable meaning. The UT may have a co-UT (ST) that has the same or different syntax features and whose meaning comes from the same or different linguistic units. In other words, a TT sentence may be a translation of a ST the unit of translation: sentence, or a clause of a sentence, or two clauses, two parts of two ST sentences, or a sentence and part of another sentence.

One of the earliest studies pertinent to Unit of Translation was done by Salimi and Shahrestani (2012). They investigated a hierarchy of units of translation (UTs) proposed by Newmark (1991) including word, phrase, clause, sentence, and paragraph in the literary translations. They also explored the relationship between the UTs and the freeliteral dichotomy in terms of the occurrence of unit/rank shifts. To this end, they gathered a corpus of three famous English novels and two best-selling translations of each to be analyzed. Through a contrastive analysis, two hundred and ten coupled pairs of ST-TT segments were extracted from the first ten pages of each novel and its two translations based on establishing relations of equivalence between the ST-TT segments and adopting sentence as the major unit of analysis. The UTs adopted in the STTT segments were then identified. Their obtained results of the UT categories demonstrated that the most frequent UT adopted by the professional literary translators was sentence. The unit-shifts applied in the UTs were also signified. The statistical calculation of frequency of unit-shifts in each translator's UTs proved that the more frequent is the occurrence of unit-shifts in the UTs of the translator, the more deviated is his translation from the formal correspondence, the more different the size of his UTs is, and finally the freer his translation will be.

In another study, Abgarmi and Shaghaghi (2017) investigated two trends exist for Persian term-formation. In the first method known as calquing, words are rendered morpheme by morpheme. Thus, the UT is a morpheme. In the second method known as conceptual equivalent-finding, the definitions of words are considered and the UT is a word. Their study was designed to identify which of the two UTs was more favored in Persian term-formation. To this end, 40 English prefixes were studied in 2354 English words together with their Persian equivalents approved by the Academy of Persian Language and Literature (APLL) as the official term-formation agency in Iran. It was noticed that calquing was more frequent, i.e. morphemes were more frequently considered as UTs. Moreover, strategies of translating prefixes were introduced and examined in both methods. In conceptual method, prefixes were ignored and not translated morpheme by morpheme. However, in calquing, English prefixes were translated into Persian prefixes or lexemes. It should be noted here that reviewing the related literature showed that no comprehensive study has been conducted on unit of translation in Iranian translation studies context. Thus, the present study is considered as a pioneer research in the field.

\section{Methodology}

This section reports on the methodology of the present study. Thus, it includes the research design, the participants, instruments, which were employed for data collection. Further, the data analysis is discussed.

\subsection{Research Design}

The method used in this study was quantitative research in nature, and the true experimental design, in the way that there were both the experimental and control groups through random selection and a treatment. There were a pre-test and a post-test for all these groups and a treatment (between the pre-test and post-test). That is, the treatment based on Unit-of-Translation was the independent variable and Iranian upper-intermediate EFL learners' achievement in Bizarre News translation was the dependent variable. It should be noted that gender of the participants was also investigated as the moderator variable.

\subsection{Participants}


45 out of 88 EFL learners from three upper-intermediate language learners at two language institutes in Boumehen, Iran were selected based on a placement test (Oxford Placement Test). Then, they were divided randomly into three groups; one control group $(\mathrm{N}=15)$ and two experimental groups. The first experimental group was male. The second experimental was female, and the third group was administered as the control group. They ranged from 21 to 29 years old. All of them were Persian native speakers.

\subsection{Research Instruments}

\subsubsection{Oxford Placement Test}

In order to check the level of general English language proficiency of the participants at the beginning of the study, and to find out a homogenous sample, an Oxford Placement Test (OPT) was used. The items of the OPT test were taken from 'Longman Complete Course for the TOEFL Test' by Philips (2017). The OPT consisted of three parts: listening comprehension, reading comprehension, and grammatical structures. The test had 100 items for which the highest score was 100. Based on the standard of the test itself, and since the items of the test were time-consuming, the allotted time was 100 minutes. This test was selected because it was inexpensive, easy to administer, and easy to score objectively. Moreover, the grammar section of OPT was expected to evaluate learners' knowledge of sentence structure. Listening section of the test consisted of 20 items in multiple-choice form followed by reading comprehension section consisting of three passages with 45 questions in multiple-choice form. The third section of the OPT aimed at testing the grammatical knowledge of participants by giving 35 questions in multiple-choice forms.

\subsubsection{Translation Proficiency Pre-test}

In addition to OPT, a standard pre-test was utilized as the other required instrument in this study to investigate the participants' initial knowledge of Bizarre News Translation. The aim was to determine whether participants were homogeneous in their knowledge of translation of Bizarre news. The pre-test was reviewed by two faculty members of the field to ensure the validity. Furthermore, to ensure its reliability, KR21 was conducted and reported (.81), which was satisfactory for the purpose of the current study.

\subsubsection{Translation Proficiency Post-test}

Another test as the post-test was administered. The only difference between this test and the pre-test was that the sequence of the items had been changed in order to avoid "practice effect" (Bachman, 1990) on the part of the participants.

\subsubsection{Corpus of the Study}

The qualitative aspect of this approach was concerned with utilizing a coherent Critical Discourse Analysis framework for Bizarre News, from 2014 to 2015 and selecting 50 Bizarre News. The interpretive framework allowed the qualitative Critical Discourse Analysis to identify and define the ideological markers and constraints, their contribution to the ideological stamp of mistranslations as well as the analysis of translation discourse within a social and cultural context at an operational level.

\subsection{Data Collection}

\subsubsection{Piloting}

One of the most important parts of the research was "piloting" because it was possible to detect the unforeseeable minute points and problems with the instruments of the main study, and in this way it prevented "a great deal of frustration and possible extra work later on" (Dornyei, 2007, p.75). Regarding this point, the researchers designed a pilot study. The most important purpose was to allocate the time limit, and find out the weaknesses of the research instruments to be eradicated in their final versions. In the pilot study, 15 participants had similar characteristics of the participants in the main study.

\subsubsection{Main Study}

The first step to carry out this study was to ensure the homogeneity of the participants at the beginning of the research; therefore, an OPT was administered to 88 female and male learners studying English in two institutes in Boumehen, Iran. Then, those participants whose scores fell one SD above and below the mean were randomly selected to take part in this study. Having analyzed the data, the researchers selected 45 participants for the purpose of this study. The OPT consisted of 100 items in the form of multiple-choice questions, and students were supposed to choose the correct 
answer from among the alternatives. The required time to complete the test was 100 minutes. The qualified participants were assigned into two experimental groups and one control group each with 15 learners. The experimental groups received the instruction for unit of translation. The instruction was given in five sequential sessions about 50 minutes. In contrast, the control group received no special instruction. At the end of the course, a post-test was administered.

\subsection{Data Analysis}

After collecting the required data of participants from proficiency test, pre-test, and post-test, the researchers put the data in SPSS program. First, to ensure the normality distribution of the data set One Sample Kolmogrove-Smirnove was run. In addition, to investigate the means of three groups one-way ANOVA was conducted. Furthermore, an independent samples t-test was administered to compare the performance of the male and female groups.

\section{Findings}

\subsection{Restatement of the Research Problem}

As mentioned earlier, the current study was an attempt to investigate whether the Unit-of-Translation had any effect on Iranian upper-intermediate EFL learners' achievement in Bizarre News translation. In addition, it investigated whether there was any difference across gender regarding the effect of Unit-of-Translation on Iranian upperintermediate EFL learners' achievement in Bizarre News translation.

\subsection{Reliability Indexes of the Research Instruments}

Before utilizing the research instruments in the current study, their reliability indexes were estimated through a pilot study on 15 EFL learners sharing similar charachteristics with the main participants of this study. Table 1 shows the reliability indexes of the research instruments.

Table 1. Reliability of research instruments

\begin{tabular}{|c|c|c|}
\hline Test & Items .1 & 2. KR- 21 \\
\hline OPT & 100 & .82 \\
\hline Pre-test & 10 & 0.79 \\
\hline Post-test & 10 & 0.81 \\
\hline
\end{tabular}

\subsection{Descriptive Statistics of the Tests}

To answer the research questions of the study, descriptive statistics of the Oxford Placement Test (OPT) are reported in Table 2.

Table 2. Descriptive statistics of the advanced placement test

\begin{tabular}{llllll}
\hline & $\mathrm{N}$ & Min. & Max. & M & SD \\
\hline OPT & 88 & 35 & 87 & 61 & 1.302 \\
Valid N & 88 & & & & \\
\hline
\end{tabular}

According to Table 2, the mean and standard deviation of OPT scores are 81 and 1.302, respectively. Based on the OPT results, 45 out of 88 language learners, whose scores were between 63 and 87 were selected. As mentioned earlier, 45 selected participants were divided into three groups as two experimental groups (one male, $\mathrm{N}=15$, one female, N=15) and a control group. Similarly, the descriptive analysis of the pre-test and post-test of the control group are presented in Table 3. 


\subsection{Descriptive Statistics of the Control Group}

Descriptive analysis of the pre-test and post-test of the control group are presented in Table 3.

Table 3. The descriptive analysis of control group

\begin{tabular}{llllll}
\hline & $\mathrm{N}$ & Min. & Max. & M & SD \\
\hline Pretest & 15 & 36 & 86 & 61 & 1.233 \\
\hline Posttest & 15 & 37 & 84 & 60.5 & 1.705 \\
\hline
\end{tabular}

As shown in Table 3, the control group's pre-test mean score is 61 ( $\mathrm{SD}=1.233)$. In addition, initial comparing the pretest results with those of the post-test score (mean=60.5, $\mathrm{SD}=1.705$ ) revealed that no much development in terms of achievement in Bizarre News translation been occurred. Moreover, Figure 1 illustrates pre-test scores for the control group.

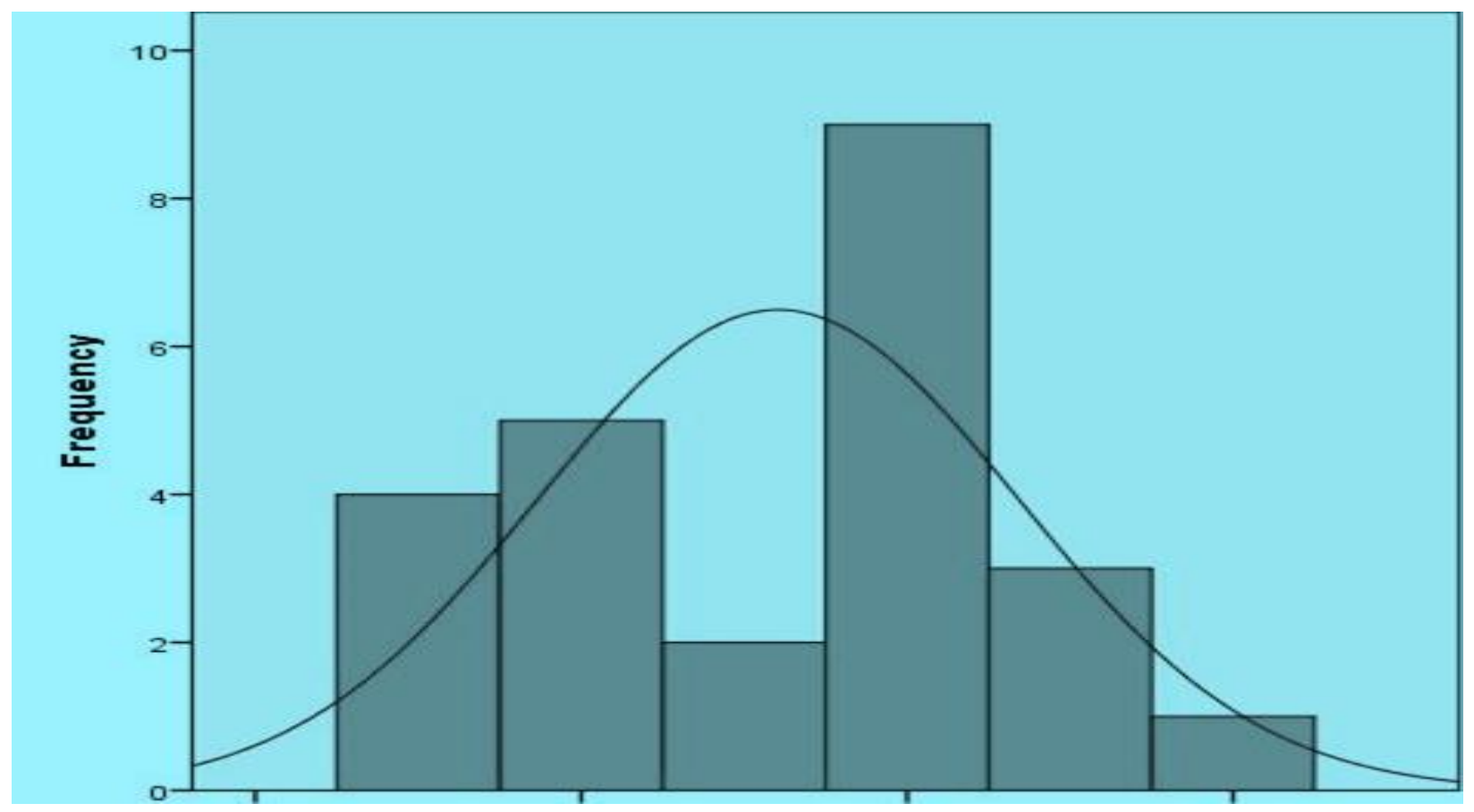

Figure 1. Pre-test of the Control Group.

In addition, the results indicated in Figure 2 illustrate the post-test scores of the control group. 


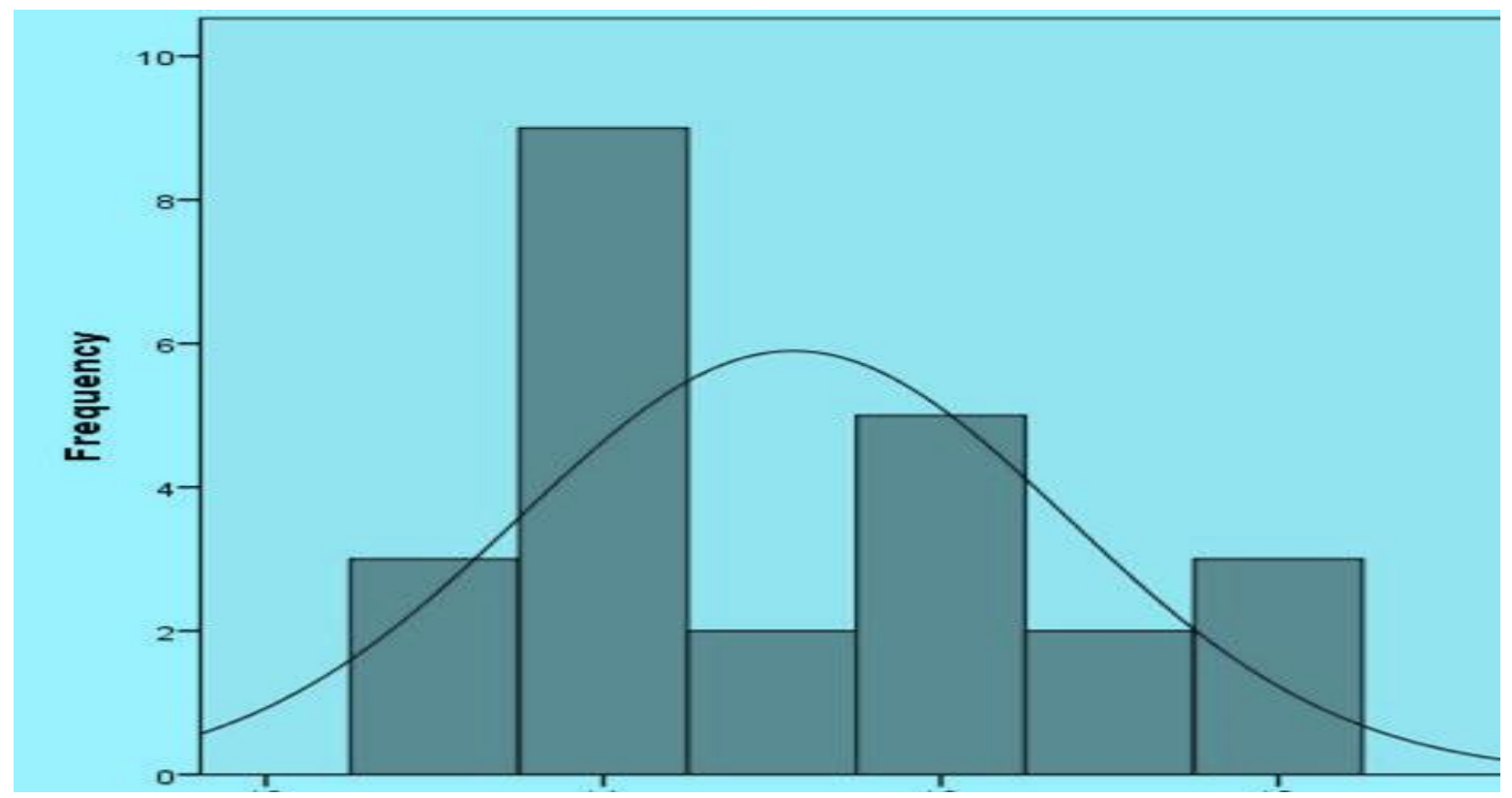

Figure 2. Post-test of the Control Group

\subsection{Descriptive Statistics of the First Experimental Group (Male Group)}

As mentioned earlier, one experimental group as the male group of the study received instruction via Unit-ofTranslation (henceforth, EMG). The results of pre-test and post-test of this experimental group are presented in Table 4.

Table 4. The descriptive analysis of EMG

\begin{tabular}{rcccccc}
\hline & & N & Min. & Max. & M & SD. \\
\hline & Pretest & 15 & 36 & 87 & 61.5 & 1.233 \\
& Posttest & 15 & 42 & 86 & 64 & 1.715 \\
Valid & & 15 & & & & \\
\hline
\end{tabular}

As shown in Table 4, the first experimental group's mean in pre-test is 61.5 with the standard deviation of 1.233; while in the post-test, the experimental group indicated a mean score of 64 with the standard deviation of 1.715. In addition, the following figures show the pre-test and post-test of this experimental group, respectively. 


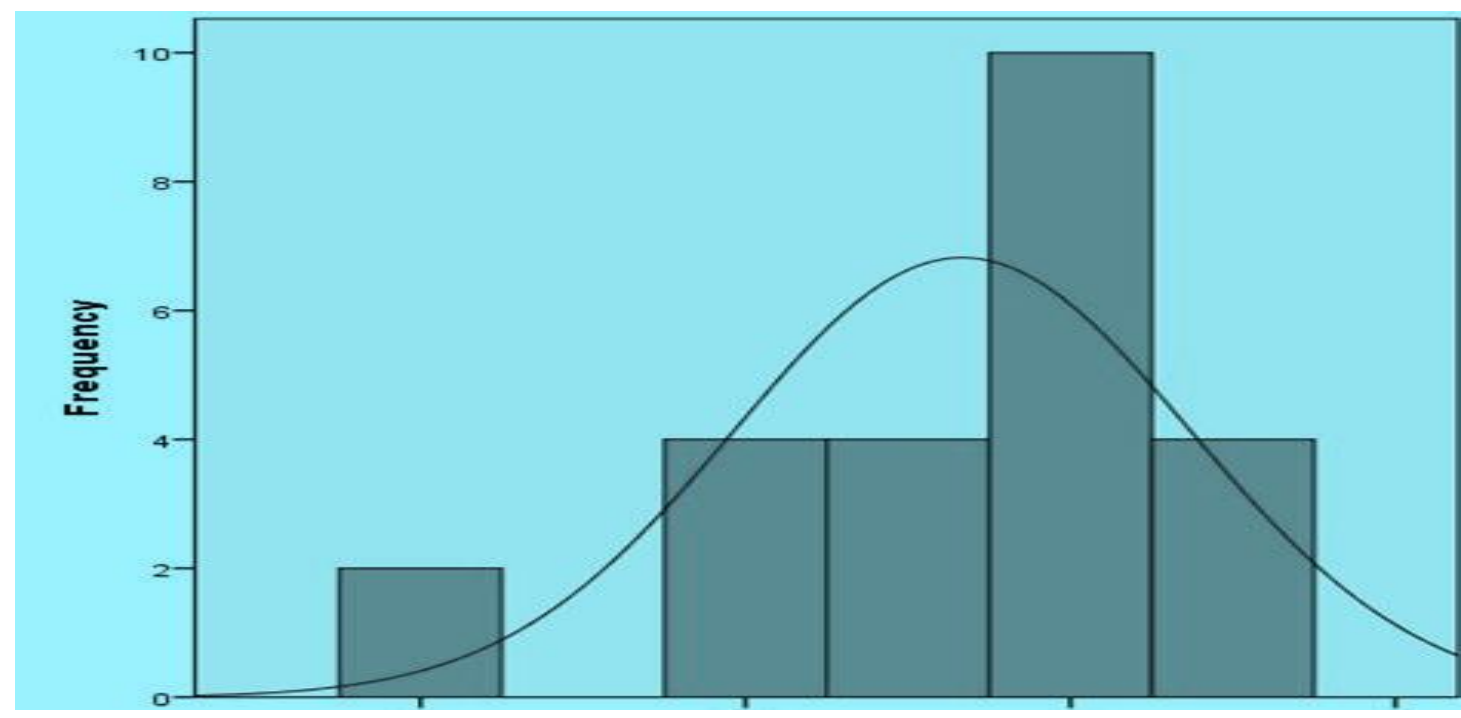

Figure 3. The pre-test of the first experimental group (EMG)

Moreover, the Figure 4 represents the post-test of this experimental group.

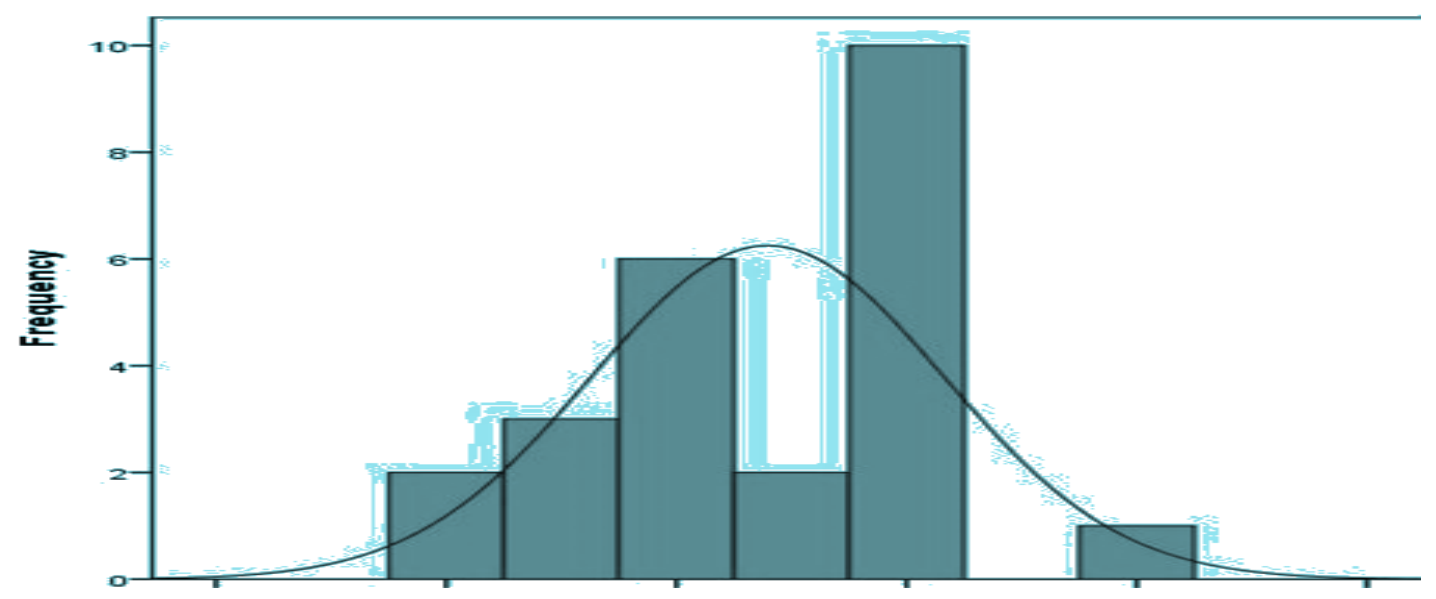

Figure 4. The post-test of the first experimental group (EMG)

\subsection{Descriptive Statistics of the Second Experimental Group (Female)}

The results of pre-test and post-test of the second experimental group (female group, henceforth, EFG) are also presented in Table 5.

Table 5. The Descriptive analysis of the second experimental group (EFG)

\begin{tabular}{llllll} 
& $\mathrm{N}$ & Min. & Max. & $\mathrm{M}$ & $\mathrm{SD}$ \\
\hline Pretest & 15 & 36 & 86 & 61 & 1.003 \\
\hline Posttest & 15 & 37 & 87 & 62 & 1.562 \\
\hline Valid N & 15 & & & &
\end{tabular}


As illustrated in Table 5, the second experimental group's mean in pre-test was 61 with the standard deviation of 1.003; while in the post-test, this experimental group indicated a mean score of 62 with the standard deviation of 1.562. In addition, the following figures showed the pre-test and post-test of this experimental group, respectively.

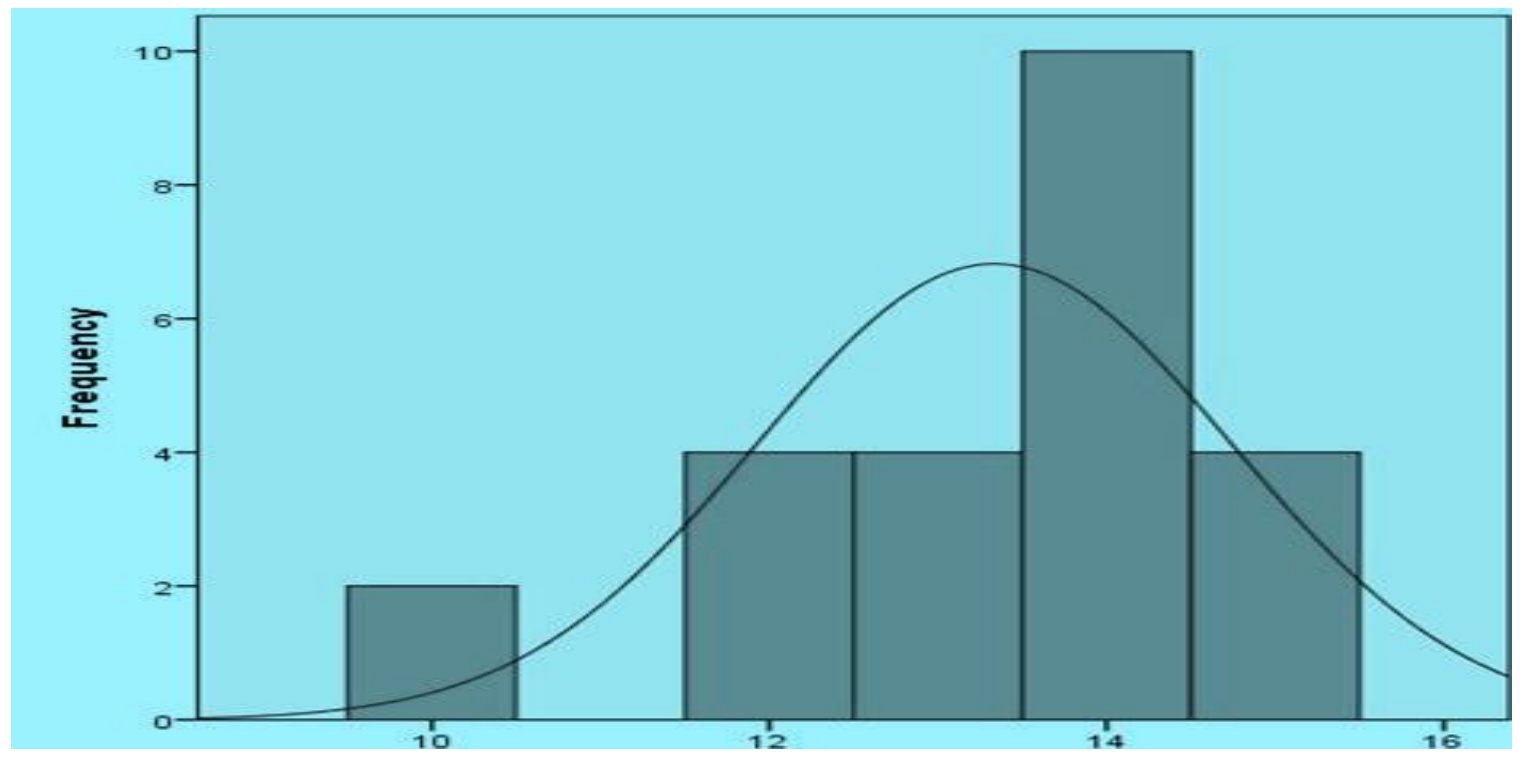

Figure 5. The pre-test of the second experimental group (EFG)

Furthermore, the following figure represents the post-test of this experimental group.

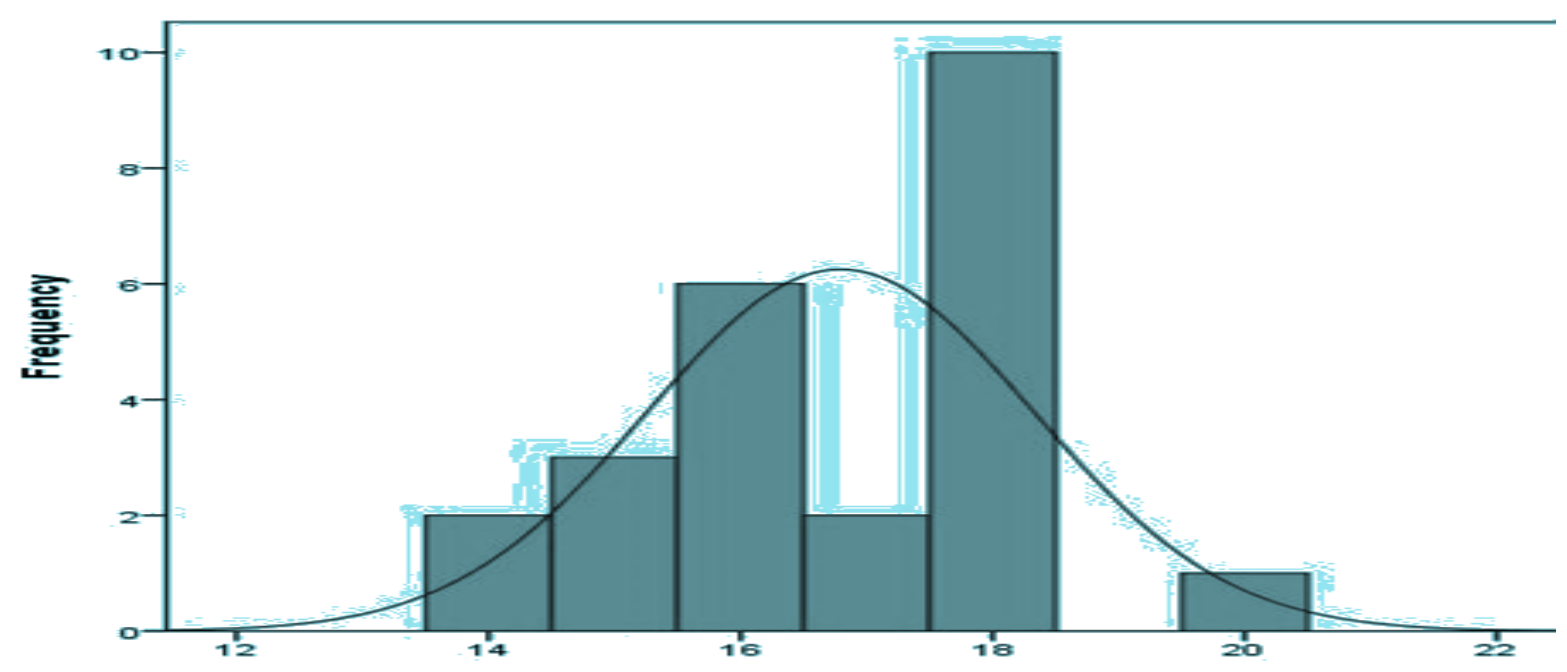

Figure 6. The post-test of the second experimental group (EFG)

In sum, the descriptive analysis of the pre-test mean scores of the study revealed that there was no significant difference between their scores, thus, it was assumed that three groups were similar in terms of their translation proficiency prior to the instruction.

\subsection{Examining the Normality}


Prior to the analysis of post-tests of three groups, to ensure the normality of data distribution, One-Sample Kolmogorov-Smirnov Test set of scores was run. Table 6 demonstrates the results of this test.

Table 6. One Sample Kolmogorov-Smirnov test

\begin{tabular}{|c|c|c|c|}
\hline & & $\begin{array}{l}\text { Posttest in Control } \\
\text { Group }\end{array}$ & $\begin{array}{l}\text { Post-test in } \\
\text { Experimental } \\
\text { Groups }\end{array}$ \\
\hline $\mathrm{N}$ & & 15 & 30 \\
\hline \multirow{2}{*}{ Normal Parameters ${ }^{\mathrm{a}, \mathrm{b}}$} & Mean & 60.5 & 63 \\
\hline & SD & 8.624 & 8.20 \\
\hline \multirow[t]{3}{*}{ Most Extreme Differences } & Absolute & .367 & 354 \\
\hline & Positive & .367 & .284 \\
\hline & Negative & -.233 & -.354 \\
\hline Kolmogorov-Smirnov & & .367 & .354 \\
\hline Asymp. Sig. (2-tailed) & & .216 & .374 \\
\hline
\end{tabular}
a. Test distribution is Normal.
b. Calculated from data.

As it is shown in Table 6, p-value for both sets of scores was higher than 0.05. Hence, the scores were normally distributed and two parametric tests of ANOVA and independent samples t-test and could be appropriate to be administered.

\subsection{Answer to Research Questions}

\subsubsection{Answer to the First Research Question}

The first research question investigated whether the Unit-of-Translation had any effect on Iranian upper-intermediate EFL learners' achievement in Bizarre News translation. To answer this question, one-way ANOVA was run to compare the performance of three groups.

Table 7. The ANOVA results

\begin{tabular}{lccccc}
\hline Source of Variance & SS & df & MS & F & Sig. \\
\hline Between groups & 511.43 & 2 & 260.72 & 50.29 & \\
Within groups & 202.66 & 44 & 4.83 & & .0035 \\
Total & 714.09 & 45 & & & \\
& & & & & \\
\hline
\end{tabular}

According to Table 7, there was model significance for the ANOVA, $F(2,44)=50.29, p<.05$, indicating at least one significant difference among the means. The main shortcoming of ANOVA lies in the fact that it provides no 
information as to the location or the source of variance (i.e. male or female group). That is, was the control group who received no special instruction significantly different from the first or second experimental groups, or was the first experimental group significantly different from the second experimental group? Therefore, in order to determine the location of difference, and to answer the first research question confidently when $\mathrm{F}$ value was significant, Scheffe post-hoc analysis was also conducted. Table 8 illustrates the results of Scheffe analysis.

Table 8. Scheffe Analysis

\begin{tabular}{lllllll}
\hline \multirow{2}{*}{ Groups } & & \multicolumn{1}{c}{$\begin{array}{l}\text { Mean } \\
\text { Difference }\end{array}$} & $\begin{array}{l}\text { Std. } \\
\text { Error }\end{array}$ & & Sig. & \multicolumn{2}{l}{$95 \%$ Confidence Interval } \\
\cline { 6 - 7 } & & & & & Lower Bound & Upper Bound \\
Control & Male G & $-2.0000^{*}$ & .51640 & .008 & -3.4395 & -.5605 \\
& Female G & $-4.0000^{*}$ & .51640 & .000 & -5.4395 & -2.56 .5 \\
Male & Control & $2.0000^{*}$ & .51640 & .008 & .5605 & 3.4395 \\
& Female G & $-2.0000^{*}$ & .51640 & .008 & -3.4395 & -.5605 \\
Female & Control & $4.0000^{*}$ & .51640 & & .5605 & .5605 \\
& Male G & $2.000^{*}$ & .51640 & & -3.4395 & 3.4395 \\
\hline
\end{tabular}

As it is presented in Table 8, the results of Scheffe test from both experimental groups in terms of the comparing the effect of Unit-of- Translation instruction revealed that the performance of both male and female groups was more significantly effective than that of the control group (Mean Difference $=-2.0000^{*}$, Std. Error $=.51640, \mathrm{Sig}=.000$ ). Thus, the answer to the first research question became clear, and its related hypothesis was rejected.

\subsubsection{Answer to the Second Research Question}

The second research question explored whether there was any difference across gender regarding the effect of Unitof-Translation on Iranian upper-intermediate EFL learners' achievement in Bizarre News translation. To this end, independent samples t-test was utilized to compare the performance of the experimental groups (Male Group \& Female Group) at the end of the instruction.

Table 9. Independent Samples T-test results

\begin{tabular}{|c|c|c|c|c|c|c|c|c|}
\hline Groups & $\mathrm{N}$ & Mea & SD & $\begin{array}{r}\text { Leven } \\
\text { Equality }\end{array}$ & $\begin{array}{l}\text { 's Test } \\
\text { of Vari }\end{array}$ & $\begin{array}{l}\text { t-test } \\
\text { ces }\end{array}$ & Equa & lity of Means \\
\hline & & & & $\mathrm{F}$ & Sig. & $\mathrm{t}$ & df. & Sig. (2-tailed) \\
\hline Group A & 15 & 64 & 1.715 & 13.928 & 0.001 & 2.494 & 44 & 0.014 \\
\hline Group B & 15 & 62 & & & & & & \\
\hline
\end{tabular}

As it can be seen in Table 9, the mean of the male experimental group is 64, and that of the female experimental group is 62 with the level of significance of .001. Since the level of Sig. is less than 0.05 set for the study, F $(2,44)=13.928$, $p<.05$ ), it can be concluded that there is a significant difference between two groups' performance in the post-test. Thus, the second research question is answered, and the second null hypothesis is also rejected. 


\section{Discussion}

The current study investigated whether the Unit-of-Translation had any effect on Iranian upper-intermediate EFL learners' achievement in Bizarre News translation. The findings revealed that the Unit-of-Translation had a positively significant effect on Iranian upper-intermediate EFL learners' achievement in Bizarre News translation. In addition, it explored whether there was any difference across gender regarding the effect of Unit-of-Translation on Iranian upper-intermediate EFL learners' achievement in Bizarre News translation. The results indicated that Iranian male upper-intermediate EFL learners had a better achievement in Bizarre News translation compared to their counterparts in the female group.

In translation studies, much discussion in the translation literature has focused on identifying what should be equivalent in a translation. For example, with regard to the linguistic form, discussion in translation literature has focused on whether equivalence is to be pursued at the level of words, clauses, phrases, sentences, paragraphs, or the entire text. Accordingly, this has given rise to the emergence of the concept of Translation Units, one of the key concepts in translation theory that has exercised translation theorists over a very long period. In the field of translation, from a product-oriented approach, a translation unit is a segment of a target text which the translator treats as a single cognitive unit. The translation unit may be a single word, or it may be a phrase, a clause, a sentence, or even a larger unit like a paragraph.

In translation studies, the issue of UT is frequently raised in conjunction with that of translation equivalence. As Sager (1994, p.222) puts it, both "lie at the heart of any theoretical or practical discussion about translation." This is because theorists, consciously or unconsciously, take the UT as a compartment in which what they believe to be "translation equivalence" materializes. There is a point in establishing equivalence, Toury believes, only insofar as it can serve as a stepping stone to uncovering the overall concept of translation underlying the corpus it has been found to pertain to; besides, the notion of equivalence may also facilitate the explanation of the entire network of translational relationship and the individual coupled pairs as representing actual translation units under the dominant norm of translation equivalence (1986).

In this regard, one of the tasks of the researcher wishing to probe into the translation units is to establish the equivalent relationships between the coupled pairs of ST and TT segments which can pave the way for the identification and classification of units of translation at different levels. In other words, to investigate unit(s) of translation that the translator chooses during the translation process, one needs to establish a relation of equivalence between the ST and the TT. The findings of the present study are in line with other studies (Abgarmi \& Shaghaghi, 2017; Salimi \& Shahrestani, 2012). Salimi and Shahrestani (2012) explored units of translation proposed by Newmark (1991) including word, phrase, clause, sentence, and paragraph in the literary translations. They also investigated the relationship between the units of translation and the free-literal dichotomy in terms of the occurrence of unit/rank shifts. Their findings showed that the most frequent UT adopted by the professional literary translators was sentence.

Additionally, the results of the current study are consistent with the findings of Abgarmi and Shaghaghi (2017). They explored two trends exist for Persian term-formation. In the first method known as calquing, words are rendered morpheme by morpheme. Thus, the UT is a morpheme. In the second method known as conceptual equivalent-finding, the definitions of words are considered and the UT is a word. It was found that strategies of translating prefixes were introduced and examined in both methods. In conceptual method, prefixes were ignored and not translated morpheme by morpheme. However, in calquing, English prefixes were translated into Persian prefixes or lexemes.

\section{Conclusion}

Translation in bilingual and multilingual contexts plays a vital role in gaining, establishing, and maintaining political and or expressing news. Understanding the reproduction of news stories through translation can be studied as function of both textual and contextual properties of the communication process by which different factors show up to influence the final outcome deliberately. Technical terminology used in news has a significant role in translation of technical or scientific texts. Specialized terminology in a text being translated, is the first signal of technical translation. The kind of intervention demanded by news translation on the original text modifies the traditional role of the translator in relation to both the author and the source text. The theory and method of news analysis must be an interpretive, constructive, and contextual approach. It means that critical discourse analysts offer interpretations of the meanings of text rather than just quantifying textual features and deriving meaning from this; situate what is written or said in the context in which it occurs, rather than just summarizing patterns or regularities in texts; and argue that textual 
meaning is constructed through an interaction between producer, text, and consumer rather than simply being read off the page by all readers in exactly the same way.

The findings, theoretical discussions, as well as practical evidences of this research can provide guidelines for novice translators who need to gain the initial knowledge to take the preliminary steps. The results of this study may introduce some usable hints on the application of the most appropriate UT in the news translation for university students majoring in translation and translation courses. Since the most frequently applied UT among the translators proved to be the 'sentence', grammar exercises and translation tasks on grammatical structures can be used in translation classes. For fulfilling such a purpose, teachers had better use a grammar-oriented approach in their translation classes, especially in courses such as translation principles and methodology, as well as translation of simple texts in general and Bizarre News texts in particular. This is due to the fact that the ST segments can have a deep structure and a surface structure whose identification can help apply the UT that is true equivalence of the ST and best fits the translation of news texts. Furthermore, based upon the relationship between the UTs and the free-literal dichotomy in terms of the unit shifts, the translation trainees can be instructed that application of unit-shifts in the process of going from the ST to the TT helps them to achieve a free translation and that the news translation needs to undergo deviations from the formal correspondence to meet this requirement.

In addition, the implications for translation studies may be significant in other aspects. Theorists can no longer afford to create UT-related theories without recognizing the UT. In fact, the translating unit is where the theorist and the practitioner meet. Thus, for a UT-related theory to be testable, the translation theorist may no longer be able to ignore or sideline the UT - the sentence in context. Last but not the least, translation units also provide a way of locating the boundary of a unit of meaning in the original text through the view of another language. Experienced translators will be aware of where the boundary of a translation unit is; in other words, they will know where the boundary of a unit of meaning is. The monosemous translation equivalent in the target language can help us to determine the unit of meaning in the original language. Moreover, as the repository of translation units and translation equivalents, parallel corpora have huge research potential, especially to bilingual or multilingual lexicography. They can be used to form or improve lexical, translation bases, word banks, or bilingual dictionaries. They are an indispensable supplement of translation aids.

\section{References}

Abgarmi, R. P., \& Shaghaghi, V. (2017). Units of translation adopted in Persian term-formation. TradTerm, São Paulo, v. 29, Junho/2017, p. 146-167. http://docplayer.net/51916133-Units-of-translation-adopted-in-persianterm-formation-unidades-de-traducao-adotadas-na-formacao-terminologica-persa.html

Altenberg, B., \& Granger, S. (2002). Recent trends in cross-linguistic lexical studies. In B. Altenberg and S. Granger (eds.), Lexis in contrast, corpus-based approaches. Amsterdam / Philadelphia: John Benjamins Publishing Company, 3-48. https://doi.org/10.1075/scl.7.04alt

Dörnyei, Z. (2007). Creating a motivating classroom environment. In J. Cummins and C. Davison (eds.), International handbook of English language teaching. Springer International Handbooks of Education, vol 15. Springer, Boston, MA. https://doi.org/10.1007/978-0-387-46301-8_47

Barkhudarov, L. (1975). Translation and translating: Theory and practice. London: Longman. https://www.academia.edu/38460208/Translation_and_Translating_Theory_and_Practice

Barkhudarov, L. (1993). The problem of the unit of translation. In Zlateva, P. (ed.), Translation as social action: Russian and Bulgarian perspectives. London: Routledge.

Breus, S. (2005). Statistics for corpus linguistics. Edinburgh: University of Tubingen. Edinburgh University Press.

Brown, D. (2000). Principle of language learning \& teaching. (4th ed). New York: Longman.

Catford, J. C. (1965). A linguistic theory of translation. Oxford: Oxford Translation Press. https://archive.org/stream/J.C.CatfordALinguisticTheoryOfTranslationOxfordUniv.Press 1965/j.+c.+catforda+linguistic+theory+of+translation-oxford+univ.+press+\%281965\%29_djvu.txt

Doherty, M. (1999). Clefts in translations between English and German. Target. International Journal of Translation Studies, 11(2), 289-315. doi: https://doi.org/10.1075/target.11.2.06doh 
Hardie, A., \& Khoja, S. (2001). Proceedings of the Corpus Linguistics 2001 conference. Lancaster: University Centre for Computer Corpus Research on Language Technical Papers, 2001. 635 p. (UCREL Technical Papers).

Hatim, B., \& Munday, J. (2004). Translation: An advanced resource book. London: Routledge. https://linguistlist.org/issues/16/16-756/

Huang, Z. (2002). Translation variation theory (in Chinese). Beijing, China Translation \& Publishing Corporation. https://www.erudit.org/en/journals/meta/2003-v48-n4-meta725/008730ar/

Karimnia, A., \& Heydari Gheshlagh, N. (2020). Investigating culture-specific items in Roald Dahl's "Charlie and Chocolate Factory" based on Newmark's model. International Journal of Research in English Education (IJREE), $\quad 5(2), \quad 1-12$. http://ijreeonline.com/article-1-326-en.html

Komissarov, A. (1999). The environments of translation. In Steiner, E., \& Yallop, C. (eds), Exploring translation and multilingual text production: Beyond content. Series text, translation, computational processing. Berlin and New York: Mouton de Gruyter.

Matthiessen, C. (2001). The environments of translation. In C. Y. Erich Steiner (Ed.), Exploring translation and multilingual text production: Beyond content (pp. 41-126). Berlin; New York: De Gruyter. https://researchers.mq.edu.au/en/publications/the-environments-of-translation

Newmark, P. (1988). A textbook of translation. New York/London: Prentice Hall. https://archive.org/stream/ATextbookOfTranslationByPeterNewmark/a\%20textbook\%20of\%20translation\% 20by\%20peter\%20newmark_djvu.txt

Newmark, P. (1991). A textbook of translation. New York, London: Prentice Hall.

Philips, S. (2017). Symbols do not create meaning - Activities do: Or, why symbolic anthropology needs the anthropology of technology. Anthropological perspectives on technology. Brian Schiffer, ed. Pp. 77-86. Albuquerque: University of New Mexico Press.

Retsker, Y. I. (1974). Teoria p erevoda i perevodcheskaia praktika (Theory of translation and translation practice). Moscow: Mezhdunarodnii otnoshenia.

Sager, J. (1994). Language engineering and translation: Consequences of automation. Amsterdam \& Philadelphia: John Benjamins. https://benjamins.com/catalog/btl.1

Salimi, D., \& Shahrestani, S. (2012). A review of translation theories. Iranian Translation Journal, 3(4), 22-40.

Sikander, A. (2018). Translation is an impossibly possible task for non-natives: An Oxymoron. International Journal of Research in English Education (IJREE), 3(4), 27-35. http://ijreeonline.com/article-1-126-en.html

Shuttleworth, M., \& Cowie, R. (1997). Dictionary of translation studies. Manchester, UK: St. Jerome Pub. https://www.worldcat.org/title/dictionary-of-translation-studies/oclc/40516996

Snell-Hornby, M. (1988/1995). Translation studies: An integrated approach. Amsterdam/Philadelphia, John Benjamins. https://www.amazon.com/Translation-Studies-integrated-Mary-Snell-Hornby/dp/1556190522

Teubert, W. (2001). Corpus linguistics and lexicography. International Journal of Corpus Linguistics, 6(1), 125-153. doi: 10.1075/ijcl.6.3.11teu

Teubert, W. (2004). Units of meaning, parallel corpora, and their implications for language teaching. In Connor, U. and T. A. Upton (eds.), Applied corpus linguistics: A multidimensional perspective (pp. 171-189). Amsterdam: Rodopi. doi: 10.1163/97890043333772_010

Torop, E. (1995). Information density and translation, with special reference to German - Norwegian - English. pp. 197-234 of: Johansson, S., \& Oksefjell, S. (eds), Corpora and cross-linguistic research: Theory, method and case studies. Amsterdam: Rodopi.

Toury, G. (1986). Descriptive translation studies and beyond. Amsterdam and Philadelphia: John Benjamins. 
Tyulenev, A. (2007). The environments of translation. Pages 41-124 of: Steiner, E., \& Yallop, C. (eds), Exploring translation and multilingual text production: Beyond Content. Series Text, Translation, Computational Processing. Berlin and New York: Mouton de Gruyter.

Vinay, J., \& Darbelnet, J. (1958). A methodology for translation: Translation studies reader (2 ${ }^{\text {nd }}$ Edition). L. Venuti. New York: Routledge, 2000. pp 128-137.

Vinay, J., \& Darbelnet, H. (1995). Comparative stylistics of French and English: A methodology for translation (translated and edited by J. Sager \& M. J. Hamel), Amsterdam \& Phladelphia: John Benjamins Publishing Company. 